\title{
Evaluation of physiology knowledge loss in medical students of Ahvaz Jundishapur University of Medical Sciences
}

This article was published in the following Dove Medical Press journal: Advances in Medical Education and Practice

\author{
Narjes Zaeemzadeh' \\ Sanaz Taherpour ${ }^{2}$ \\ Noor Behzadian ${ }^{2}$ \\ Seyyed Ali Mard ${ }^{2}$
}

'Deparment of Phamacology, The School of Pharmacy, Medical Educational and Development Center (EDC), Ahvaz Jundishapur University of Medical Sciences, Ahvaz, Iran; ${ }^{2}$ Physiology Research Center (PRC), Department of Physiology, School of Medicine, Medical Educational and Development Center (EDC), Ahvaz Jundishapur University of Medical Sciences, Ahvaz, Iran
Correspondence: Seyyed Ali Mard Physiology Research Center (PRC), Department of Physiology, School of Medicine, Medical Educational and Development Center (EDC), Ahvaz Jundishapur University of Medical Sciences, Esfand Street, Golestan District, Ahvaz, 6133573 I I8, Iran

Tel +989166118532

Fax +98 6II $33624 I I$

Email mard-sa@ajums.ac.ir
Purpose: The knowledge loss or longevity of taught lessons is a major concern in medical students and all medical practitioners. This study evaluated the physiology knowledge loss in medical students in Ahvaz Jundishapur University of Medical Sciences in Iran.

Methods: A total of 265 volunteers from medical students who had previously passed the "general exam of medical basic sciences" at the end of fifth semester took a retention test (RT) to evaluate their knowledge loss of physiology. The candidates were divided into ten groups depending on the semester (S) they were passing at the time of study: 41 students in preclinical levels (S6 and S7), 123 students in externship levels (S8, S9, S10, S11 and S12), and 101 students in internship levels (S13, S14 and S15). The RT consisted of 20 multiple choice questions from all topics of medical physiology, including central nervous system, endocrine, gastrointestinal, cardiovascular, respiratory, renal, blood, and cellular.

Results: Findings showed that there was a decreasing trend of knowledge loss from S6 to S15. The lowest level of knowledge loss was observed in S15 students. These results also demonstrated that knowledge loss in male medical students was more than that in female students.

Conclusion: These findings indicated that the physiology knowledge loss trend is inversely correlated with the time passing. We conclude that the reason is that physiology is a basic science which is most applicable during medical students' clinical years.

Keywords: Ahvaz, Iran, medical students, physiology, knowledge loss, retention test, female student

\section{Introduction}

Traditional medical education is not highly focused on applying the basic sciences to clinical years. In such a system the most important issue is getting good marks in the exams. ${ }^{1}$ However, the medical students should obtain their clinical knowledge on the basis of basic science knowledge which has been taught previously. ${ }^{2}$ There is a direct relationship between the basic science taught earlier in medical school and the later performance during medical school and even beyond that. ${ }^{3}$ Therefore, if there is a clinical concept while students are learning basic science knowledge, this can help them to make a competent clinical diagnosis afterwards. ${ }^{4}$

Many senior medical students believe that there is little or no relevance between their knowledge obtained in the first years of education and the clinical practice. ${ }^{5}$ Most physicians also believe that the basic science knowledge in medical education is forgotten while the medical students complete the clinical courses. ${ }^{6}$ In medical domains, approximately one third to one fourth of the basic knowledge will be lost after 1 year has passed. ${ }^{7}$ Cole says that it is "disuse atrophy" which has happened to basic sciences 
knowledge during the years of clinical exposure. ${ }^{8}$ This loss is sometimes more severe in special courses like anatomy ${ }^{9}$ and biochemistry. ${ }^{10,11}$ Some researchers say that this loss may be more if the syllabus that is being taught is not associated with clinical concepts directly. ${ }^{12}$ Learning basic science knowledge confidently in a clinical context is better comprehended and more easily applied by the students. ${ }^{13,14}$ On the other hand, some investigators say that the basic science loss may not always happen after years. ${ }^{15}$ Perhaps physicians do not have enough confidence on their memory of basic knowledge after some years. ${ }^{16}$ In almost all publications on knowledge retention in different domains of medical basic sciences (anatomy, immunology, physiology, neuroanatomy, biochemistry, microbiology, pathology, and pharmacology), there is a record of knowledge loss; however, the quantity of retention has a wide range from $38 \%$ to $94 \% .^{2,5,10,17-20}$ There is only a little record of knowledge increments in pharmacology, pathology, and behavioral sciences, as time is passing. ${ }^{10,11,21,22}$

In Iran there is a 15-semester-long conventional medical curriculum which included five semesters of basic science knowledge. Among basic syllabuses physiology and anatomy are the most overloaded syllabus of basic sciences in Iran medical curriculum. Some students claim that anatomy, biochemistry, and physiology courses should be decreased to cover only the general aspects to be more useful practically. ${ }^{23}$

On the other hand, more than $85 \%$ of medical students say that physiology is among the most important issues that are needed for understanding the clinical cases. ${ }^{23}$ Fortunately about half of the medical students in Alam's study claim that physiology is the most retained basic knowledge too. ${ }^{1}$ Another study showed that $65.3 \%$ of medical students could well recall physiology and that along with anatomy these two were the most recalled courses. ${ }^{23}$

The quantity of the knowledge remembered (retention) is an important issue, as it seems that the formal education system of teaching basic sciences in medical faculties is only a waste of time and energy if the medical students cannot use their basic knowledge afterwards in the clinical sectors. ${ }^{24}$

Regarding the importance of physiology in the medical training programs as mentioned before, this study aimed to evaluate how the knowledge of physiology which is taught in the first 2 years of medical education in Ahvaz Jundishapur University of Medical Sciences (AJUMS) is affected by time. We also assayed the relationship between retention intervals (RI $=$ the period of nonuse) and the percentage of knowledge loss.

In this university, the organization started a process named integration in medical education. This has two parts. At first they accomplished the horizontal part of it, which means that the basic sciences are taught organ-based. The second part of it is vertical which is opposed by some authorities because of multiple reasons. The vertical section is pertained to the integration of basic sciences and clinical sectors. If the results of this survey indicate that physiology is strongly needed in clinical sectors, we can use them to support the vertical integration to be done in medical education.

\section{Methods}

This study was conducted on a total of 265 volunteers of medical students of both sexes from $6^{\text {th }}$ to $15^{\text {th }}$ semester (female: $58.1 \%$ and male: $41.9 \%$ ) in AJUMS. This survey did not require an approval statement of ethics committee, because it does not interfere with any treatment or basically any physiological or pathological condition in the body. These types of studies do not need ethical approval in this institute (Ahwaz Jundishapur University of Medical Sciences). In addition the exam taken was completely optional. The candidates were divided into ten groups depending on the semester (showed as "S") they were spending at the time of study: 41 (21 in S6, 20 in S7) students in preclinical levels, 123 students in externship levels (21 in S8, 28 in S9, 23 in $\mathrm{S} 10,25$ in S11, 26 in S12), and 101 students in internship levels (24 in S13, 37 in S14, 40 in S15). All the participants had previously passed the "general exam of medical basic sciences" at the end of fifth semester.

A retention test (RT) was held in winter 2014. The students were not aware in advance about the test and the test sheets were unnamed.

The RT consisted of 20 multiple choice questions to evaluate the retention of physiology knowledge. Each question was followed by four answers, only one of them was correct. The questions were selected from a pool of questions of the past ten exams of "general medical basic sciences." The selected questions covered all the topics of physiology which had been previously taught to these students according to the university curriculum. The number of questions in each area was determined by the quantity of that special topic in the detailed physiology headings, and it was as below: respiratory system (2), cardiovascular system (4), blood (1), gastrointestinal tract (2), neurophysiology (4), endocrine system (3), cell (2), and kidney (2). Here are some examples of questions:

- Which condition can decrease the pulse pressure?

A: Hyperthermia.

B: Aortic valve stenosis.

$\mathrm{C}$ : Aortic valve insufficiency.

D: Atherosclerosis. 
- Which of the following factors can decrease the glomerular filtration rate?
A: Acetylcholine.
B: Norepinephrine.
C: Dopamine.
D: Prostaglandin E2.

- What happens if the gastric vagus nerve is cut down? A: The intramural pressure of stomach rises, while gastric volume is increasing.

B: Resting intramural pressure of the stomach rises.

$\mathrm{C}$ : Gastric acid secretion increases in the gastric phase.

D: Somastatin secretion increases in the cephalic phase.

- Which action is related to thyroid hormones?

A: Decreasing carbohydrate intestinal absorption.

B: Decreasing plasma cholesterol due to increasing the low density lipoprotein receptors.

$\mathrm{C}$ : Increasing the time of tension reflexes when there is hyperthyroidism.

D: Increasing gene expression of cathecholamine receptors when there is hypothyroidism.

- Which of the following EEG waves appears in REM sleep?
A: Alpha.
B: Beta.
C: Delta.
D: Theta.

One point was allocated for a correct answer and nothing for a blank or incorrect answer. The time needed for the test was considered 20 minutes, exactly similar to the time considered in the "general exam of medical basic sciences" (1 minute for each question).

The average score of physiology in the "general exam of medical basic sciences" and the score of RT were expressed as crude score from a maximum of 20 points. The answers were manually checked and scored.

For each group in various semesters the average score of the RT was compared to the average score of the physiology section of "general exam of medical basic sciences" obtained by all the students of the same group.

In this study retention intervals (RIs; the time period between the RT and the "general exam of medical basic sciences") were $0.5,1,1.5,2,2.5,3,3.5,4,4.5$, and 5 years for S6 to S15 students, respectively, at the time of holding the RT. The S6 students had freshly passed the "general exam of medical basic sciences" and the S15 students were very close to graduation.

The percentage of knowledge loss in each of the ten groups was calculated according to the following formulas:
First, (the mean score of RT of each group / the mean score of the physiology section of "general exam of medical basic sciences" obtained by the same group) $\times 100=\mathrm{A}$

Second, $100-\mathrm{A}=$ the percentage of knowledge loss.

\section{Statistical analysis}

Data were analyzed using one-way ANOVA followed by least significant differences statistical tests. Paired sample and independent sample $t$-tests were respectively used for comparing the score of RT and the average score of physiology in the "general exam of medical basic sciences" for each group, and for comparing the amounts of knowledge loss between male and female medical students. The results were expressed as mean \pm SEM. $P<0.05$ was considered as significant.

\section{Results}

All participants had passed physiology courses within 2 years (four consecutive semesters). As shown in Figure 1, there was a decreasing trend of knowledge loss from S6 to S15. The mean \pm SEM of knowledge loss for S6-S15 were S6: 60.88 \pm 3.39 ,

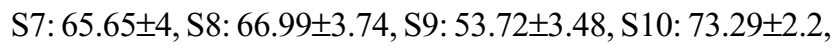
S11: 54.62 $2.59, \mathrm{~S} 12: 42.9 \pm 2.78, \mathrm{~S} 13: 42.64 \pm 3.32, \mathrm{~S} 14$ : 45.63 \pm 2.51 , and S15: 23.02 \pm 3.33 . The lowest level of knowledge loss was observed in the S15 students. As illustrated in Figure 2, the overall amount of knowledge loss in male medical students was more than that in female students $(P<0.01)$. The mean \pm SEM of knowledge loss for male and female students were $7.53 \pm 0.32$ and $6.53 \pm 0.25$, respectively.

\section{Discussion}

In AJUMS like almost all other medical universities in Iran, the medical education curriculum includes 2.5 years of basic

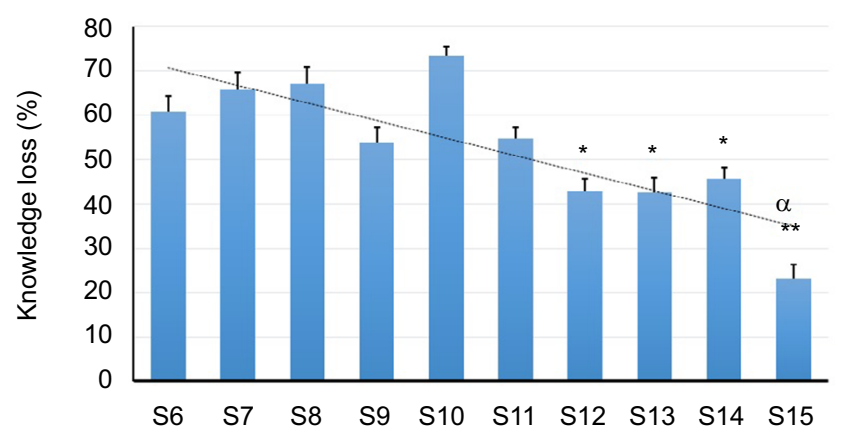

Figure I The percentage of knowledge loss among the medical students in Ahvaz Jundishapur University of Medical Sciences.

Notes: The percentage of knowledge loss among medical students showed a decreasing trend from $S 6$ to $S 15$. "S" represents the semester. ${ }^{*} P<0.05$, and ${ }^{* * P} P<0.0 \mathrm{I}$ as compared with $\mathrm{S} 6-\mathrm{SII}$. ${ }^{\alpha} \mathrm{P}<0.0 \mathrm{I}$ compared with $\mathrm{SI} 2-\mathrm{SI} 4$. 


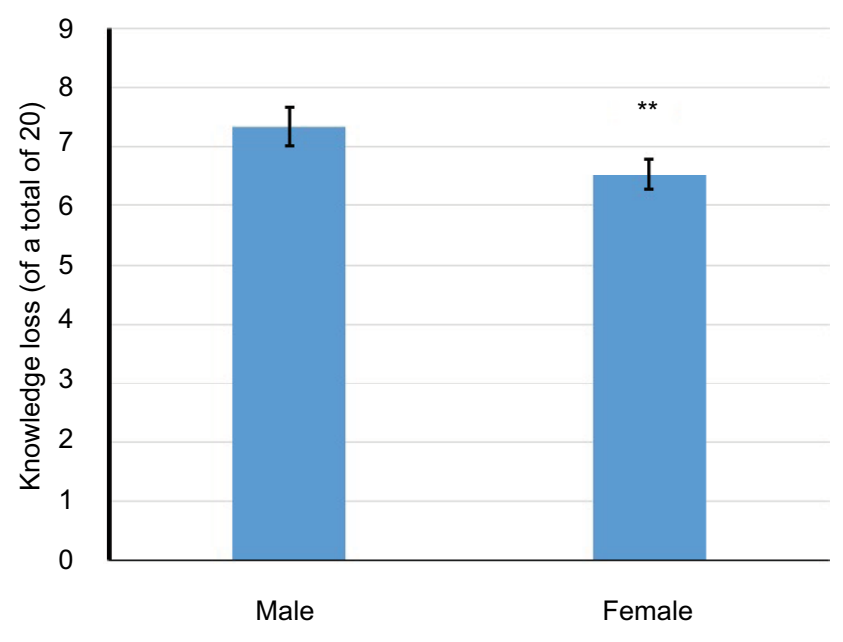

Figure 2 The amount of knowledge loss between male and female medical students. Note: This amount was more in male students than in female medical students $(* * P<0.01)$.

science education including physiology and anatomy, as the most overloaded syllabuses. This five-semester period is followed by 1 year which is named "Physiopathology" and includes theoretical courses of internal medicine, pathology, and pharmacology; this is the same "preclinical" level mentioned previously (semester 6 and 7) and is mainly lecture-based. Afterwards they would spend the last 4 years of their study (externship and internship training periods) which keep them in close contact with patients in various clinical sectors at the university hospitals. In the externship period (2.5 years, semester 8-12), they are in direct contact with the patients in the hospital, but are not allowed to treat. They can only observe and pursue the treatment protocols. In the following internship (1.5 years, semester 13-15), they are closely linked to the treatment procedures and in some cases they do the therapy themselves but under close supervision.

It is a general fact that passing the time impresses the retention of knowledge. ${ }^{2}$ This is seen in all groups of students in our study too and we had no group without knowledge loss.

Of unrehearsed knowledge, approximately one-third will be forgotten over the course of 1 year and 50\%-60\% will be lost over 2 years. ${ }^{24}$ Afterwards forgetting continues, but at a consistent decreasing rate; it means that the longer the RI, the less is the knowledge retention (or the more is the knowledge loss). ${ }^{24}$ Surprisingly, we could not see this in our study, and it is observed there is a decelerating trend of knowledge loss over a time period of 5 years (from semester 6 to 15$)$. It can be due to the highest applicability of physiology among the basic sciences, during the practical clinical stages of medical study. ${ }^{1}$ This is confirmed by three separate studies which all claim that the retention percentage in physiology is 80 or even more; the RIs in these studies varied from 15 weeks to 2 years. ${ }^{5,10,25}$ The issue of increasing retention of basic knowledge in the clinical years of exposure in medical students in the presence of increasing RIs was also obtained in our previous study which had assessed pharmacology knowledge loss. ${ }^{26}$

This improvement suggests that the exposure of medical students to the clinical sectors which are started in $8^{\text {th }}$ semester in Iran medical curriculum can intensify the prior knowledge of some basic sciences including physiology. The reason maybe frequent flashbacks to physiology while they are involved with the treatment of patients as Alam says about the highest use of physiology among the basic sciences in clinical years. ${ }^{1}$ Also recalling the mechanism of action of almost all drugs would force them to come back to physiology. If these review studies were small in number or do not exist at all, like something which usually happens to the subjects like biochemistry, it would not have great effect on the retention of knowledge. ${ }^{24}$ This is confirmed by Bahrick who states that data retention can be unchanged even for up to 30 years in our "permastore" (permanent storage) of human brains. ${ }^{27}$

Our results showed that there is a significant difference between the knowledge loss in the students in S6-S8 and those in S12. As it was mentioned previously about Iranian medical curriculum, the students who are in S12 will enter the internship courses in a very near future. They should pass a general entrance exam to be permitted to enter this period, and this can be the main cause of their lesser knowledge loss, because they would prepare for the entrance exam. Another reason may be their 2.5 years. practical experience with the patients in the externship courses.

The students in S15 also had significant decrease in knowledge loss when compared to the students in S13-S14. As mentioned earlier, the students in S15 are next to graduation and the reason for their lesser knowledge loss might be their greater experience in managing patients than students in S13-S14; they have 1 year of internship experience which the students in S13-S14 do not have. Another explanation for this difference is the higher rate of responsibility which they have been given by their supervisor than the students in S13-S14.

Our finding also showed a significant increase in the amount of knowledge loss in male students in comparison with females. This was parallel to Laiacona et al study which mentioned that a sexual asymmetry exists in semantic memory tasks in a way that a disproportionate deficit of 
information about plants reported more frequently in male patients; albeit the study was performed in brain damaged individuals. ${ }^{28}$ Also significant sex differences, favoring women, were found for tasks assessing episodic memory. ${ }^{29}$

Overall the retention quantity or on the other hand knowledge loss is related to other factors like teaching quality and student performance which have neither been assessed nor are generally easy to assess.

\section{Conclusion}

Our results showed that the physiology knowledge loss trend is inversely correlated to increments in retention time. The reason is that physiology is a basic science issue which has the highest applicability in clinical years that a medical student spends.

According to the results of this survey, physiology is strongly needed in clinical sectors. If we can teach physiology courses along with clinical topics, it will be more effective for comprehending the pathophysiology of disease in the patients who are being assessed. This is a support for the authors to convince the authorities of the university to perform the second part of integration (vertical) in medical education which is previously mentioned in the Introduction.

\section{Acknowledgments}

This study was financially supported by the Vice Chancellor of Research Affairs of AJUMS (grant number U-93135). The authors thank Dr Laleh Zaeemzadeh, gynecologist and obstetrician, for English editing of the manuscript.

\section{Disclosure}

The authors report no conflicts of interest in this work.

\section{References}

1. Alam A. How do medical students in their clinical years perceive basic sciences courses at King Saud university? Ann Saudi Med. 2011;31(1): 58-61.

2. Lazić E, Dujmović J, Hren D. Retention of basic sciences knowledge at clinical years of medical curriculum. Croat Med J. 2006;47(6):882-887.

3. Hojat M, Gonnella JS, Erdmann JB, Veloski JJ. The fate of medical students with different levels of knowledge: are the basic medical sciences relevant to physician competence? Adv Health Sci Educ Theory Pract. 1996;1(3):179-196.

4. Malau-Aduli BS, Lee AY, Cooling N, Catchpole M, Jose M, Turner R. Retention of knowledge and perceived relevance of basic sciences in an integrated case-based learning (CBL) curriculum. BMC Med Educ. 2013;13(1):139.

5. D'Eon MF. Knowledge loss of medical students on first year basic science courses at the University of Saskatchewan. BMC Med Educ. 2006;6(1):5.

6. Norman G. The essential role of basic science in medical education: the perspective from psychology. Clin Invest Med. 2000;23(1):47-51; discussion 2-4.
7. Custers EJ. Long-term retention of basic science knowledge: a review study. Adv Health Sci Educ Theory Pract. 2010;15(1):109-128.

8. Cole L. What is wrong with the medical curriculum? Lancet. 1932;220(5683):253-254.

9. Bethe A. Kritische Betrachtungen über den vorklinischen Unterricht (Critical enforcement in the preclinical course). $J$ Mol Med. 1928;7(31):1481-1483.

10. Kennedy WB, Kelley PR, Saffran M. Use of NBME examinations to assess retention of basic science knowledge. J Med Educ. 1981;56(3): $167-173$.

11. Ling Y, Swanson DB, Holtzman K, Bucak SD. Retention of basic science information by senior medical students. Acad Med. 2008;83(10 Suppl):S82-S85.

12. Harris JA, Heneghan HC, Mckay DW. The rating of pre-clerkship examination questions by postgraduate medical students: an assessment of quality and relevancy to medical practice. Med Educ. 2003;37(2): 105-109.

13. Patel VL, Evans DA, Kaufman DR. Reasoning strategies and the use of biomedical knowledge by medical students. Med Educ. 1990;24(2): 129-136.

14. Dahle LO, Brynhildsen J, Behrbohm Fallsberg M, Rundquist I, Hammar M. Pros and cons of vertical integration between clinical medicine and basic science within a problem-based undergraduate medical curriculum: examples and experiences from Linköping, Sweden. Med Teach. 2002;24(3):280-285.

15. Ellis JA, Semb GB, Cole B. Very long-term memory for information taught in school. Contemp Educ Psychol. 1998;23(4):419-433.

16. Conway MA, Cohen G, Stanhope N. On the very long-term retention of knowledge acquired through formal education: twelve years of cognitive psychology. J Exp Psychol Gen. 1991;120(4):395-409.

17. Blunt MJ, Blizard PJ. Recall and retrieval of anatomical knowledge. $\mathrm{Br}$ J Med Educ. 1975;9(4):252-263.

18. Dubois AB, Nemir P, Schumacher CF, Hubbard JP. Graduate medical education in basic sciences. J Med Educ. 1969;44(11):1035-1043.

19. Herzig S, Linke RM, Marxen B, Börner U, Antepohl W. Long-term follow up of factual knowledge after a single, randomised problem-based learning course. BMC Med Educ. 2003;3(1):3.

20. Levine HG, Forman PM. A study of retention of knowledge of neurosciences information. J Med Educ. 1973;48(9):867-869.

21. Rodriguez R, Campos-Sepulveda E, Vidrio H, Contreras E, Valenzuela $\mathrm{F}$. Evaluating knowledge retention of third-year medical students taught with an innovative pharmacology program. Acad Med. 2002;77(6):574-577.

22. Saffran M, Kennedy WB, Kelley Jr PR. Retention of knowledge of pharmacology by U.S. and Canadian medical students. Trends Pharmacol Sci. 1982;3:461-463.

23. Gupta S, Gupta A, Verma M, Kaur H, Kaur A, Singh K. The attitudes and perceptions of medical students towards basic science subjects during their clinical years: a cross-sectional survey. Int J App Basic Med Res. 2014;4(1):16-19.

24. Custers EJ, Ten Cate OT. Very long-term retention of basic science knowledge in doctors after graduation. Med Educ. 2011;45(4):422-430.

25. Weitman M. A study of long-term retention in medical students. $J$ Exp Educ. 1964;33(1):87-91.

26. Zaeemzadeh N, Mard SA, Khosravi M, Lajmirnia M, Sedighi A. Pharmacological knowledge loss among medical students in Ahvaz Jundishapur University of Medical sciences. South East Asian J Med Educ. 2016;10(2):60.

27. Bahrick HP. Semantic memory content in permastore: fifty years of memory for Spanish learned in school. J Exp Psychol Gen. 1984;113(1):1-29.

28. Laiacona M, Barbarotto R, Capitani E. Human evolution and the brain representation of semantic knowledge: is there a role for sex differences? Evol Hum Behav. 2006;27(2):158-168.

29. Yonker JE, Eriksson E, Nilsson LG, Herlitz A. Sex differences in episodic memory: minimal influence of estradiol. Brain Cogn. 2003;52(2):231-238. 
Advances in Medical Education and Practice

Dovepress

\section{Publish your work in this journal}

Advances in Medical Education and Practice is an international, peerreviewed, open access journal that aims to present and publish research on Medical Education covering medical, dental, nursing and allied health care professional education. The journal covers undergraduate education, postgraduate training and continuing medical education

including emerging trends and innovative models linking education, research, and health care services. The manuscript management system is completely online and includes a very quick and fair peer-review system. Visit http://www.dovepress.com/testimonials.php to read real quotes from published authors.

Submit your manuscript here: http://www.dovepress.com/advances-in-medical-education-and-practice-journal 